Temporal stability of lower order ability scores and intelligence profiles in high ability students

Moritz Breit, Vsevolod Scherrer, \& Franzis Preckel

University of Trier

Final accepted version, 01-Apr-2021 (in press, Intelligence).

DOI: $10.1016 /$ j.intell.2021.101538

This preprint may differ slightly from the final, copy-edited version of record. 


\begin{abstract}
Individuals' general intelligence is highly stable over time and strong empirical evidence supports its validity for diagnostic purposes. Frequently, general intelligence is assessed as a composite of different specific cognitive abilities (e.g., verbal, numerical, figural ability). In previous research, these specific abilities only showed marginal stabilities, challenging their validity for diagnostic purposes. However, this research was conducted with samples of predominantly average or low ability individuals. According to Spearman's law of diminishing returns, high ability individuals show more pronounced differences between subtest scores or intelligence profiles than regular ability individuals. Therefore, we aimed to investigate the stabilities of specific abilities and intelligence profiles in high ability individuals. Using the Berlin structure-of-intelligence test (BIS-HB), we investigated the 6-month mean-level change, individual-level change, differential continuity, and ipsative continuity of specific abilities in a sample of 114 students $(28.9 \%$ female; age $M=14.11, S D=.84)$ attending special gifted classes. We found significant mean-level change for all specific abilities. Reliable individual-level increases in performance were observed for, on average, $15.4 \%$ of the participants on each

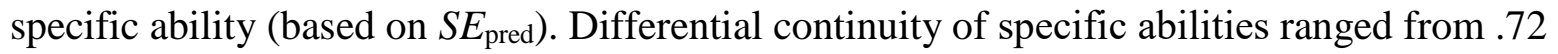
to .84 . Intelligence profiles replicated across test-retest occasions significantly above chance levels $\left(M d n_{\kappa}=.32\right)$. The results render more precisely the usefulness of interpreting intelligence profiles, which has previously been called into question in general.

Keywords: test-retest stability, reliability, intelligence profiles, Spearman's law of diminishing returns
\end{abstract}


Temporal stability of lower order ability scores and intelligence profiles in high ability students

The temporal stability of intelligence test scores is important because tests of intelligence are frequently used to support intervention decisions that have long-term consequences, such as placement into special education programs. If a trait is not sufficiently stable for many months or even years, no long-term recommendations should be given based on this trait (see Cronbach \& Snow, 1977). General intelligence has consistently been found to be a highly stable trait (Hunt, 2010; Mackintosh, 1998) and tests of general intelligence are among the most frequently used and valid tools for diagnostic purposes in psychological assessment (Nisbett et al., 2012). However, general intelligence scores are not the only scores that can be used to inform intervention decisions. Assuming a hierarchical structure of intelligence (e.g., Schneider \& McGrew, 2018), multidimensional intelligence tests also provide a set of lower-order ability scores, based on a subset of the subtests, that indicate more specific aptitudes. Based on these subtest scores or composite scores built from the subtests, authors often encourage practitioners to interpret different profiles of cognitive strengths and weaknesses, guiding their identification in the manual instructions (e.g., Kaufman, 2004; Wechsler, 2014). To justify these recommendations, empirical evidence for the temporal stability of lower-order composite scores is required. In this article, we refer to these lower-order composite scores as "specific ability scores" because they indicate performance in sets of subtests associated with the respective specific abilities. These specific ability scores comprise both general factor variance and specific group factor variance.

\section{Types of Temporal Stability}

When examining the temporal stability of specific ability scores, four different types of stability can be investigated (Fryer \& Elliot, 2007). Mean-level change represents the average 
change of a score over a period of time. This type of stability can be measured with a pairedsamples $t$ test. Individual-level change represents the change of a score exhibited by an individual. The reliable change index (RCI; Jacobson \& Truax, 1991) can be used to categorize participants as showing a significant increase, decrease, or no significant change. If change is random, the distribution of RCI values should be normal, with about $95 \%$ of the participants showing no significant change (Fryer \& Elliot, 2007). The most relevant stabilities for the interpretation of ability profiles are the differential continuity and the ipsative continuity (Canivez \& Youngstrom, 2019). Differential continuity represents the rank-order consistency of a score. It can be measured with test-retest correlations. Ipsative continuity represents the stability of an individual's configuration of different scores over time. There are different methods of investigating this kind of stability. For example, the coefficient kappa (Cohen, 1960) can be used to quantify the degree of agreement in the classification of individual strengths and weaknesses between test and retest. Combining the results of the different stability analyses provides a more complete assessment of temporal stability than each one alone (Fryer \& Elliot, 2007). For an overview of types of stability and the methods applied in this article, see Table 1.

\section{Temporal Stability of Specific Ability Scores}

\section{Mean-level change.}

Most studies investigating the temporal stability of specific ability scores report meanlevel changes in the specific ability scores. In many studies, the mean changes between test and retest are small ( $<2$ IQ points) and often statistically non-significant for different test-retest intervals (Ryan, Glass, \& Bartels, 2010; Watkins \& Canivez, 2004; Watkins \& Smith, 2013). Estevis, Basso, and Combs (2012) found significant increases of WAIS-IV specific ability scores with three- to six-month test-retest intervals (between 5 and 9 IQ points). A recent meta-analysis 
of retest effects in cognitive ability tests reports significant gains in performance when tests are taken repeatedly, with an average increase of 0.28 standard deviations for the first retest (Scharfen, Peters, \& Holling, 2018). Several moderator analyses were conducted in this metaanalysis. The size of the retest effects differed by cognitive operations, with memory tasks showing larger gains than processing speed tasks, which showed no gains. Further, the retest effect decreased with larger test-retest intervals. The decrease was small, however, with only 0.04 standard deviations per year. Intelligence and age were not significant moderators of the retest effect.

\section{Individual-level change.}

Estevis et al. (2012) also examined individual-level change in the WAIS-IV specific ability scores with three- to six-month test-retest intervals. They found that most participants did not score reliably better or worse on the retest, despite the significant average increase of the different specific ability scores.

\section{Differential continuity.}

Several studies have investigated the differential continuity of intelligence subtest scores and specific ability scores. The results are often troubling. Analyzing the test-retest reliability of the WISC-R subtest scores in a special education sample (retest interval of 3 years, $N=189$ ), McDermott, Fantuzzo, Glutting, Watkins and Baggaley (1992) found stability coefficients too low for individual diagnostic decisions $\left(M_{r}=.50\right)$. Examining the stability of scores on the WISC-IV in a sample of children with learning disabilities (retest intervals of 3 years, $N=131$ ), Lander (2010) found only small retest stability coefficients $\left(M d n_{r}=.58\right)$. Similarly, calculating WISC-IV test-retest stability coefficients in a sample of children enrolled in special education 
programs (retest intervals of 3 years, $N=344$, mean IQ $=90.32$ ), Watkins and Smith (2013) found stability coefficients only acceptable for group decisions $\left(M_{r}=.69\right)$.

In educational practice, students tested for special education program eligibility are often tested repeatedly. From the studies presented above, it is evident that this population is overrepresented in differential continuity research. Investigations of differential continuity in the general population have been rare, and the results have been conflicting. Williams Jr, Eaves, Woods-Groves, and Mariano (2007) calculated the 14-month stability of the Verbal Reasoning, Abstract Reasoning, Quantitative Reasoning, and Memory scores of the Slosson Full-Range Intelligence Test (SFRIT; Algozzine, Eaves, Mann, \& Vance, 1993) in a sample of 103 students $($ mean IQ $=103.58)$, finding retest stability coefficients between .80 and .85 . Estevis et al. (2012) examined the three- to six-month stability of the WAIS-IV specific ability scores in 54 adults $($ mean IQ $=111.6)$, finding retest stability coefficients between .72 and .86. Conversely, Ryan et al. (2010) found low specific ability score retest stability coefficients (between .49 and .75) for the 11-month stability of the WISC-IV scores in a small sample of elementary and middle school children $(N=43$, mean IQ $=111.63)$.

\section{Ipsative continuity.}

The results for ipsative continuity are, to our knowledge, completely based on samples with below-average intelligence. McDermott, Fantuzzo, Glutting, Watkins and Baggaley (1992) analyzed the classificatory stability of relative cognitive strengths and weaknesses of the WISCR subtests with a special education sample (retest interval of 3 years, $N=189$ ) and found stability coefficients below chance levels. Watkins and Canivez (2004) also investigated the classificatory stability of relative cognitive strengths and weaknesses of the WISC-III subtests and specific ability scores in a large sample of children (retest interval of 6 months to 6 years, $N$ 
$=579$, mean IQ $=88.80$ ). They found that cognitive strengths and weaknesses replicated at chance levels, independent of the test-retest interval.

The combined results of the available studies on differential and ipsative continuity led Canivez and Youngstrom (2019, p. 221) to conclude that "strengths and weaknesses obtained from cognitive profile analyses typically have minimal longitudinal stability.” Ryan et al. (2010, p. 71) stated that "subtest profiles are typically unstable and should not be used for diagnostic and/or decision-making purposes." However, based on the fact that these studies were often (differential continuity) or always (ipsative continuity) based on low ability samples, there is reason to question the generalizability of these findings to all ability groups.

\section{Spearman's Law of Diminishing Returns}

Spearman's law of diminishing returns (SLODR, also known as ability differentiation) refers to the phenomenon that the contribution of general intelligence to specific subtest scores decreases with increasing ability, whereas the overall factor structure of intelligence remains stable across the whole ability range (Hartmann \& Nyborg, 2004). That is, the correlations between specific ability scores decrease with individuals' increasing general intelligence, giving rise to more differentiated strengths and weaknesses or ability profiles. There is evidence for the effect from a wide variety of intelligence measurements (Blum \& Holling, 2017; Hartmann \& Nyborg, 2004). A number of factor analytic studies have shown that the effect is also present in adolescent samples (Breit, Brunner, \& Preckel, 2020; Reynolds, 2013; Tucker-Drob, 2009). Based on these findings, Reynolds (2013) recommended that practitioners pay greater attention to ability profiles in high ability individuals, as different patterns of specific ability scores may indicate the aptitude for different giftedness programs and career trajectories. 
A number of related findings support this recommendation. Lohman, Gabrell, and Lakin, (2008) found that extreme discrepancies in abilities are more common among gifted students than among children of average ability. There is also evidence that these profiles predict longterm development and career trajectories (Lubinski, 2010; Lubinski \& Benbow, 2006; Lubinski, Webb, Morelock, \& Benbow, 2001; Makel, Kell, Lubinski, Putallaz, \& Benbow, 2016; Robertson, Smeets, Lubinski, \& Benbow, 2010). Intelligence profiles were also found to be associated with stable academic interest profiles (Lubinski et al., 2001). Moreover, there is some evidence for greater incremental validity of specific ability scores beyond general intelligence for the explanation of academic achievement in high ability students than for average or low ability students (Breit \& Preckel, 2020; McGill, 2015).

Taken together, the presented literature indicates that intelligence profiles are more differentiated and more predictive for academic and vocational achievement in high ability individuals. Their predictive validity for vocational decisions and their associaton with stable interest profiles suggest that these ability profiles should also have substantial temporal stability.

\section{Developmental Differentiation}

The correlations between specific ability scores may not only decrease with increasing cognitive ability, but also with increasing age (Garrett, 1946). This is referred to as age differentiation or, more precisely, as the developmental differentiation hypothesis. If the correlations between specific ability scores decrease with age, this means that the importance of the $g$-factor diminishes. As the temporal stability of the $g$-factor is considered an important source of stability of specific ability scores (Canivez \& Youngstrom, 2019), this implies that the stability of specific ability scores might diminish in comparison to the stability of the $g$-factor over the course of cognitive development. However, previous studies investigating 
developmental differentiation in adolescents failed to find evidence for the effect (Breit et al., 2020; Molenaar, 2020; Molenaar et al., 2010; Schroeders et al., 2015).

\section{Methodological Considerations}

When investigating the different types of temporal stability, there are some methodological difficulties to consider. First, differential continuity is examined through correlation coefficients assessing the rank-order consistency maintained in the individual scores over time. To the extent that the specific abilities share variability with general intelligence (e.g., high factor loadings), the positive values of these autocorrelations can alternatively be explained by the stability of general intelligence. Thus, isolated interpretation of the autocorrelations can be misleading. If individual intelligence profiles are interpreted, it is vital that the stability of the specific ability scores is not due only to the stability of the shared general intelligence variance (Canivez \& Youngstrom, 2019).

Second, ipsative continuity is often assessed by Cohen's kappa, which is a widely used measure of interrater reliability. This index depicts the changes in an individual's configuration of the different ability scores over time by calculating the degree of agreement between test and retest classifications of strengths and weaknesses. However, the kappa coefficient is affected by an uneven distribution of the classification categories (Byrt, Bishop, \& Carlin, 1993). It may therefore be advisable to complement the kappa analyses with a stability index that does not exhibit this distortion, like Cramér's V.

\section{The present study}

In the present study, we investigate the medium-term mean-level change, individual-level change, differential continuity, and ipsative continuity of specific ability scores from the Berlin structure-of-intelligence test (BIS-HB) in a sample of intellectually gifted adolescents over a 6- 
month time interval. Few studies have assessed the differential continuity of intelligence profiles in average ability participants, and none have assessed high ability participants. Additionally, there have been no studies examining ipsative continuity in average or high ability samples. Thus, our analyses contribute to answering the question of whether past findings on the temporal stability of specific ability scores generalize to high ability individuals. Additionally, the present study represents the first analysis of the temporal stability of the BIS-HB specific ability scores.

Based on the meta-analyses by Scharfen et al. (2018), we expected a significant meanlevel increase in all specific ability scores, except the processing speed score. We expected to find no reliable individual-level change based on the findings by Estevis et al. (2012). Regarding differential stability, we expected higher test-retest-coefficients for the specific ability scores than reported in previous studies based on samples of regular or low ability individuals (e.g., Lander, 2010; Ryan et al., 2010; Watkins \& Smith, 2013). This expectation was based on the findings regarding SLODR and the long-term predictive validity of ability profiles for academic achievement in high ability individuals (Lubinski, 2016). In addition, we investigated the differential continuity of the specific ability scores beyond general intelligence (i.e., partial autocorrelations of the specific ability scores controlling for general intelligence) as an exploratory research question as this was not investigated in previous research. Finally, we expected higher ipsative continuity of relative cognitive strengths and weaknesses than reported in previous studies (e.g., Watkins \& Canivez, 2004) in accordance with the findings regarding SLODR. Here, we calculated two different indices of ipsative continuity, expanding on the analyses conducted in previous research.

Because differentiation effects are relevant to the temporal stability of test scores, we additionally performed an analysis of ability differentiation (SLODR), developmental 
differentiation, and the change of ability differentiation between the two measurements (i.e., interaction of ability and developmental differentiation). We expected to find ability differentiation, but no developmental differentiation or interaction effect.

\section{Method}

\section{Participants and Procedure}

The sample of the present study comprised 114 adolescents from a gifted track of a German grammar school. The participants were drawn from the standardization sample of the BIS-HB (Jäger et al., 2006). The BIS-HB was administered twice, with a test-retest interval of six months. The test was administered in the classroom according to standard procedures in a group setting (Jäger et al., 2006). The age range of the sample was 12.67 to 15.67 years $(M=$ 14.11) at the time of the first testing; 81 of the participants were male (71.1\%) and 33 were female (28.9\%). 47 participants were in $7^{\text {th }}$ grade $(41.2 \%)$, 42 participants were in $8^{\text {th }}$ grade (36.8\%), and 25 participants were in $9^{\text {th }}$ grade $(21.9 \%) .112$ participants reported German to be their first language (98.2\%). Mean IQ of the participants in the first testing was $M=116.7$ ( $S D=$ 9.97). The data for this study was collected in 2002 and 2003. All parents of the participants gave written informed consent in accordance with the Declaration of Helsinki. The protocol was approved by the principals of the participating schools. Because the analyses of this study represent secondary analyses of data collected as part of the standardization of the BIS-HB, the approval of the institutional review board of [blinded] was not sought.

\section{Instrument}

The BIS-HB (Jäger et al., 2006) is a paper-and-pencil intelligence test designed to capture the intelligence structure over the full range of cognitive ability, with a focus on the testing of 
intellectually gifted adolescents. It can be administered both individually and in group settings. Numerous studies support the construct validity and the test-criterion validity of the BIS-HB (e.g., Freund \& Holling, 2007; Freund, Holling, \& Preckel, 2007; Preckel, Holling, \& Wiese, 2006; Preckel, Wermer, \& Spinath, 2011; Vock, Preckel, \& Holling, 2011). The BIS-HB is based on the Berlin Intelligence Structure model (BIS; Jäger, 1984; Süß \& Beauducel, 2005; see Figure 1), which is historically the most prominent and influential intelligence model in Germanspeaking countries (Beauducel \& Kersting, 2002). The BIS is a faceted model comprised of an operation facet for Reasoning (R), Processing Speed (S), Creativity (C), and Memory (M) and a content facet for Figural (F), Numerical (N), and Verbal (V) ability. The two facets are conceptualized as orthogonal to each other, forming 12 cells defined by one operation and one content domain (e.g., reasoning - verbal, RV). Beauducel and Kersting (2002) investigated the relations between BIS operations and the model of fluid and crystallized intelligence. They found that Reasoning and Memory were closely associated with fluid intelligence, whereas Creativity and Processing Speed were associated with both fluid and crystallized intelligence. The BIS-HB provides specific ability scores for each operation ability $(\mathrm{R}, \mathrm{S}, \mathrm{C}, \& \mathrm{M})$ and domain ability (F, $\mathrm{N}, \mathrm{V}$ ) for ipsative profile analyses. The specific abilities scores are calculated as the sum of the subtest scores associated with the respective specific ability, similar to other multidimensional intelligence tests like the WISC-V (Wechsler, 2014). The correlations between all specific ability scores for both test and retest are presented in Table 2. Mean scores for test and retest are presented in Table 3, skewness and kurtosis are presented in Table 4. 


\section{Analyses}

For a detailed description and demonstration of the statistical methods used in this paper, see Breit et al. (2021).

\section{Mean-level change.}

The mean difference between test and retest was calculated for each specific ability score. Paired-samples $t$ tests were used to determine statistical significance. In addition, we calculated Cohen's $d$ as an effect size of mean level change.

$d=\frac{M_{t 2}-M_{t 1}}{S D_{t 1}}$

\section{Individual-level change.}

There are different methods to calculate the reliable change index. Estevis et al. (2012) proposed basing the index on the standard error of prediction $\left(S E_{\text {pred }}\right)$ when investigating intelligence tests, which can be calculated as

$$
S E_{\text {pred }}=S D_{t 2} \cdot \sqrt{\left(1-r_{t t}^{2}\right)}
$$

Here, $S D_{\mathrm{t} 2}$ is the standard deviation of scores at retest, $r_{t t}$ is the test-retest correlation. The $95 \%$ confidence interval is computed by multiplying the $S E_{\text {pred }}$ by $+/-1.96$.

Iverson (2018) recommends basing the reliable change scores on the standard error of difference $\left(S E_{\text {diff }):}\right.$

$$
S E_{d i f f}=\sqrt{\left.\left.\left(S D_{t 1} \cdot \sqrt{\left(1-r_{t t}\right.}\right)\right)^{2}+\left(S D_{t 2} \cdot \sqrt{\left(1-r_{t t}\right.}\right)\right)^{2}}
$$

The $95 \%$ confidence interval is computed by multiplying the $S E_{\text {diff }}$ by $+/-1.96$. We report results based on both methods.

Moreover, due to practice effects in intelligence testing, Estevis et al. (2012) recommend using a true score estimate for the second test score: 
$Y_{\text {TRUE }}=M_{t 1}+r_{t t}\left(Y_{\text {OBS }}-M_{t 1}\right)$

Here, $M_{t q}$ is the mean at T1 and $Y_{O B S}$ is the score observed in the retest. We used the true scores and the RCI estimates to calculate the percentage of individuals with a significant increase, decrease, or no change for each score.

\section{Differential continuity.}

Pearson product-moment correlation coefficients between the test and retest scores were calculated for the seven specific ability scores and the general ability score to assess differential stability. The resulting stability coefficients were also corrected for variability of the sample. The Pearson correlation is not sensitive to differences in profile elevation (e.g., Terracciano \& McCrae, 2006). However, in practice it performs equally well or better than alternative measures of profile agreement (McCrae, 2008). Moreover, changes in profile elevation are not relevant to the question of differential continuity; therefore, they are examined separately in the analyses of mean level change. In addition to the Pearson correlations, we computed stability coefficients controlling for general intelligence. Lastly, we calculated the profile reliability using the formula provided by Lienert and Raatz (1998):

$$
\operatorname{prof}_{t t}=\frac{\overline{r_{t t}}-\overline{r_{t T}}}{1-\bar{r}_{t T}}
$$

Here, $\bar{r}_{t t}$ is the mean reliability (in this case, the differential continuity) of all scores included in the profile, and $\overline{r_{t T}}$ is the mean intercorrelation of these scores. Differential continuity values corrected for range restriction can be used to calculate the corrected profile reliability. The profile reliability increases as the reliability of the scores increases and their average intercorrelation decreases. Lienert and Raatz (1998) considered profile reliabilities of .5 or larger to be sufficient for profile interpretation. 


\section{Ipsative continuity.}

Individual cognitive strengths and weaknesses were identified by calculating the critical difference between the general intelligence score and the individual specific ability scores for both test and retest using the formula provided by Lienert (1989):

$D_{c r i t}=1.96 \cdot S D_{G x} \cdot \sqrt{2-\left(r_{g}+r_{G x}\right)}$

$S D_{G x}$ represents the population standard deviation. $r_{g}$ and $r_{G x}$ represent the reliability of general intelligence and of the respective lower order score. Each ability was categorized as a relative weakness, a relative strength, or as unremarkable if it did not significantly deviate from the mean subtest score.

Ipsative continuity of the categorizations was quantified with coefficient kappa (Cohen, 1960) to assess ipsative continuity. Kappa is a chance-corrected metric for estimating agreement for nominal scale data:

$\kappa=\frac{P_{o}-P_{e}}{1-P_{e}}$

$P_{o}$ is the observed agreement among raters, meaning the extent to which strengths and weaknesses at $\mathrm{T} 1$ are still identified as the same at $\mathrm{T} 2$, and $\mathrm{P}_{\mathrm{e}}$ is the probability of chance agreement. We reported Cohen's kappa to make our results comparable to the results of previous research (e.g., Watkins \& Canivez, 2004). However, the kappa coefficient is affected by an uneven distribution of the classification categories. If one category is much more prevalent than the others, kappa results become unreasonably low (Byrt et al., 1993). As most specific ability scores are usually classified as unremarkable in intelligence testing, the prevalence of this category is much higher than the others. To also include an undistorted parameter, we calculated Cramér's V, which is a transformation of $\chi^{2}$ : 


$$
V=\sqrt{\frac{\chi^{2}}{n(s-1)}}
$$

Here, $\mathrm{s}$ denotes the number of categories. The interpretation of this parameter is comparable to the interpretation of other correlation coefficients (Wirtz \& Caspar, 2002).

\section{Differentiation Analyses}

Tucker-Drob (2009) introduced a nonlinear factor analysis approach to differentiation research in cross-sectional data. We adapted this method for our longitudinal data. All models were run in Mplus 8 (Muthén \& Muthén, 2017) using the full information maximum likelihood estimation method. Alpha values for testing statistical significance were set to .01 as multiple models (5) and model parameters (max. 16) were calculated.

A one-factor model with general intelligence affecting all observed specific ability scores at both times of measurement ( $\mathrm{T} 1$ and $\mathrm{T} 2$ ) was the basis for all models. Five stepwise factor models successively introduced the differentiation effects and their interaction. In Model 1, at both $\mathrm{T} 1$ and $\mathrm{T} 2$, each indicator was predicted by linear loadings on the common factor. The common factors and the indicators were allowed to covary between times of measurement. In Model 2a, terms for quadratic common factor loadings were added, modeling ability differentiation (SLODR). Negative values indicate ability differentiation (i.e., the influence of $g$ on observed subtest scores diminishes with increasing levels of $g$ ), whereas positive values indicate ability dedifferentiation. In Model 2b, the common factor loadings of the indicators were constrained to be equal between times of measurement. A significant decrease in model fit compared to Model 1 indicates a difference in the factor loadings between T1 and T2. If the factor loadings descriptively increase from $\mathrm{T} 1$ to $\mathrm{T} 2$, this indicates developmental dedifferentiation. If the factor loadings descriptively decrease from $\mathrm{T} 1$ to $\mathrm{T} 2$, this indicates developmental differentiation. In Model 3, the Models $2 \mathrm{a}$ and $2 \mathrm{~b}$ were combined to estimate 
ability and developmental differentiation simultaneously. A significant decrease in model fit compared to Model 2a again indicates a difference in the factor loadings between $\mathrm{T} 1$ and $\mathrm{T} 2$. Finally, in Model 4, the interaction effect was introduced by constraining the quadratic common factor loadings to be equal between $\mathrm{T} 1$ and T2. A significant decrease in model fit compared to Model 3 indicates a difference in the quadratic factor loadings between T1 and T2. If the factor loadings descriptively increase from $\mathrm{T} 1$ to $\mathrm{T} 2$, this indicates a positive interaction of the differentiation effects. If the factor loadings descriptively decrease from $\mathrm{T} 1$ to $\mathrm{T} 2$, this indicates a negative interaction of the differentiation effects.

The BIS-HB content (Figural, Verbal, Numerical) and operation (Processing Speed, Memory, Creativity, Reasoning) scores are partially based on the same task material, as each test task is classified by a content-operation combination (e.g., Verbal - Reasoning). Because of this, a $g$-factor model, as it is required for the differentiation analyses, does not fit the data well. We therefore performed the differentiation analyses only based on the operation scores.

\section{Results}

The mean general intelligence score (IQ) of the sample in the first test was 116.72 (125.48 in the retest), placing the sample on average one standard deviation above the population mean. The standard deviation of the general intelligence score was 9.97 (9.61 in the retest), and the standard deviation of the specific ability scores ranged from 9.66 to 12.80 (9.64 to 13.04 in the retest). In the BIS-HB standardization sample, standard deviations of the specific ability scores range from 15.16 to 16.39 , indicating a range restriction in the present sample. In addition to uncorrected results, we therefore report results corrected for range restriction when applicable. 


\section{Mean-level change}

We found a significant increase in full IQ scores from test to retest (8.78 IQ points, $d$ $=.90 ;$ Table 3 ). All specific ability scores also increased significantly. The increase ranged from 5.60 IQ points ( $d=.27$; Reasoning) to 10.29 IQ points $(d=.89$; Figural Ability). The mean increase was 7.92 IQ points $\left(M_{d}=.61\right)$.

\section{Individual-level change}

The percentage of participants who showed a reliable increase, decrease, or no reliable change are presented in Table 5. Using the $S E_{\text {pred }}$ for the calculation of the reliable change index, most participants showed no reliable change of their score. However, a considerable percentage of participants showed an increase in specific abilities, ranging from 5.3\% (Creativity) to $23.7 \%$ (Processing Speed). Averaging across the different specific abilities, reliable increases were observed for $15.4 \%$ of the participants. Only five participants showed reliable decrease in an ability. 30.7\% showed a reliable increase in general intelligence.

Using the $S E_{\text {diff }}$ for the calculation of the reliable change index, the results were similar, but on average showed slightly less reliable increases in ability. Specific abilities reliably increased for $4.4 \%$ (Creativity) to $23.7 \%$ (Processing Speed) of the participants, with an average of $13.5 \%$ of participants. Only two participants showed a reliable decrease in an ability. $29.8 \%$ showed a reliable increase in general intelligence.

\section{Differential continuity}

The differential continuity coefficients for all BIS-HB scores are presented in Table 6. The general intelligence score was the most stable with $r=.82$ (.93 when corrected for range restriction). The stability coefficients of the specific ability scores ranged from .72 to .84 . (.78 - .93 corrected for range restriction). Stability was the lowest for Memory and Creativity scores 
with .74 and .72 (.80 and .78 corrected for range restriction) and the highest for Processing Speed and Reasoning with .84 (.91 and .93 corrected for range restriction). There are no established standards for differential continuity required for individual diagnostic decisions, but based on the recommendations of Watkins and Smith (2013), the obtained uncorrected stability coefficients could be considered in the range of the lowest acceptable values, whereas the corrected stability coefficients can safely be considered to be sufficiently high. Interestingly, some specific ability stability coefficients were comparable to the stability of general intelligence (Processing Speed, Reasoning, Numerical Ability, Verbal Ability).

When controlling for General Intelligence scores, the test-retest correlations were still substantial $\left(r_{12 . g}=.49-.69\right)$. Thus, $24 \%$ to $48 \%$ of the retest score variability could be explained by the earlier test score, independent of the stability of the general intelligence score. The partial correlations were somewhat higher for the operation scores (.55-.69) than for the content scores (.49-.53).

Lastly, we obtained a profile reliability of ${ }_{\text {prof }} r_{t t}=.53$ using the uncorrected stability coefficients, which can be considered adequate for individual diagnostic decisions, and ${ }_{\text {prof }} r_{t t}$

$=.71$ when using the stability coefficients corrected for range restriction.

\section{Ipsative continuity}

The ipsative continuity coefficients for all BIS-HB scores are presented in Table 7. For Numeric Ability, no coefficients could be computed because no participants showed statistical significant strength or weakness in this ability at T1. The median kappa coefficient of the remaining six specific ability scores was .34 and ranged from .23 (Verbal Ability) to .58 (Creativity). All statistical tests were significant $(p<.01)$. The kappa values for Processing Speed, Memory, Reasoning, Figural Ability, and Verbal Ability can be categorized as 
demonstrating fair continuity $(.25-.34)$, and the value for Creativity as moderate continuity (Landis \& Koch, 1977).

Cramér's $V$ ranged from .22 (Processing Speed) to .65 (Creativity). All statistical tests were significant $(p<.01$; Processing speed $p<.05)$. The continuity of Processing Speed, Memory, and Verbal Ability were weak $(V=.22-.34)$, whereas the values for Creativity, Reasoning, and Figural Ability indicated moderate continuity $(V=.43-.65)$.

\section{Differentiation analyses}

Absolute model fit could only be determined for Model $1(\mathrm{CFI}=.990, \mathrm{RMSEA}=.056$, SRMR $=.053)$. The standardized model loadings supported the appropriateness of the $g$-factor model $\left(\lambda_{1}=.438-.852\right)$. The indicator error variances were allowed to covary between measurements $(r=.627-.810)$. Table 8 reports the relative model fit of the different models. Table 9 reports the relevant model parameters of all models.

\section{Ability differentiation}

There was no uniform pattern of $g^{2}$-loadings, indicating neither the consistent presence of ability differentiation nor ability dedifferentiation. No $g^{2}$-loadings were statistically significant in Model 2a. Results were similar for the other model with unrestricted $g^{2}$-loadings (Model 3). The introduction of the ability differentiation effect did not improve model fit (Model 2a versus Model 1), further corroborating the absence of any substantial ability differentiation effect.

\section{Developmental differentiation}

In the unrestricted Model 1, the Processing Speed and Creativity g-loadings increased descriptively, whereas the other loadings decreased. This inconsistent pattern supported neither developmental differentiation nor developmental dedifferentiation. When the unstandardized $g$ loadings were restricted to be equal between Grade 5 and Grade 7, the model fit did not 
deteriorate (Model 2b versus Model 1, Model 3 versus Model 2a). These results indicate the absence of any developmental (de-)differentiation.

\section{Interaction}

The interaction effect can be evaluated by observing the changes of indicator $g^{2}$-loadings $\left(\lambda_{2}\right)$ from T1 to T2. Descriptively, the Memory $g^{2}$-loading increased whereas the other loadings decreased. When the unstandardized $g^{2}$-loadings were restricted to be equal between the times of measurement, the model fit did not deteriorate (Model 4 versus Model 3). These results indicate the absence of a significant interaction effect.

\section{Discussion}

We analyzed the different types of temporal stability for seven specific ability scores in a sample of high ability students. In contrast to previous research based on regular or low ability individuals, the results consistently indicated stabilities acceptable for individual diagnostic decisions.

\section{Mean-level Change}

Mean levels of all specific ability scores and general intelligence increased significantly. We expected an increase in all specific ability scores except for Processing Speed. However, the Processing Speed score increased the most of all operation scores. In general, we found higher increases than reported in the meta-analysis by Scharfen et al. (2018), with a mean increase of $d$ $=.61$. Although it may appear plausible that the highly intelligent sample was able to benefit more from previous test experience, Scharfen et al. (2018) did not find intelligence to be a moderator of the retest effect.

\section{Individual-level Change}


A considerable percentage of participants showed a reliable increase in specific ability scores and general intelligence. This result is somewhat surprising, as Estevis et al. (2012) reported shorter average test-retest intervals (as utilized in this study) were associated with fewer reliable ability increases. It is possible that the extensive promotion in the giftedness track quickly led to large gains in intelligence. For the question of whether specific ability scores are less stable than general intelligence and therefore less suitable for individual diagnostic decisions, it is relevant to observe that the specific ability scores did not show reliable change more or less often than the general intelligence score. In our analyses, this was not the case.

\section{Differential Continuity}

The differential continuity coefficients were consistently higher than those reported in previous studies investigating individuals of below-average cognitive ability. We found an average differential continuity of $M_{r}=.79\left(M_{\text {rcorrected }}=.87\right)$. Previous studies reported values of $M_{r}=.69\left(M_{\text {rcorrected }}=.73\right.$; Watkins \& Smith, 2013), $M d n_{r}=.58\left(\right.$ Lander, 2010) and $M d n_{r}=.66$ (Ryan et al., 2010). In addition, we still observed considerable positive autocorrelations of the specific ability scores even after controlling for general intelligence. Thus, the high observed differential stabilities are largely based on the stability of unique specific ability score variance, not the stability of general intelligence. Put simply, differential continuity means that an individual who performed better than another person on a given specific ability score was likely to still perform better on this score six months later. Crucially, due to the significant partial correlations, this cannot be explained purely by a difference in general intelligence. The high differential continuity, especially when controlling for general intelligence, is in line with our expectations based on SLODR. If ability profiles are more pronounced in high ability 
individuals, one would expect higher stabilities of the associated index scores, even when controlling for general intelligence.

\section{Ipsative Continuity}

Similarly, we found an ipsative continuity of $M d n_{\kappa}=.32\left(M d n_{\mathrm{V}}=.44\right)$, compared to $M d n_{\kappa}$ $=.02$ reported by Watkins and Canivez (2004). Interestingly, we found that one of the specific ability scores with the highest differential continuity (Processing Speed) showed one of the lowest ipsative continuity coefficients. This finding illustrates that results of differential continuity and ipsative continuity analyses are not identical. A substantial ipsative continuity indicates that an individual who performed exceptionally better in one specific ability (e.g., Memory) compared to his or her average performance in the other specific abilities was likely to still perform much better in this specific ability than in the other specific abilities six months later. Our results indicate moderate ipsative continuity, meaning that whereas many participants

showed comparable strengths and weaknesses over time, a substantial number of participants did not. The relatively high ipsative continuity compared to previous studies is in line with our expectations based on SLODR. If ability profiles are more pronounced in high ability individuals, one would expect higher temporal stability of these profiles as well.

\section{Differentiation effects}

We found no evidence for ability differentiation in our data. The absence of ability differentiation may be due to the highly selective sample and the enriched educational context. In our stability analyses, we assumed that our high ability sample showed higher stabilities of specific ability scores than usually reported because of ability differentiation. This assumption is not challenged by not finding evidence for ability differentiation in our sample, as there may still be a difference in intelligence structure differentiation between our highly selective sample and 
the regular population. The absence of developmental differentiation and of the interaction effect was not surprising, as support for these effects in the literature is tenuous (Blum \& Holling, 2017; Hartmann \& Nyborg, 2006; Tucker-Drob, 2009). Moreover, the interval of six months is too short to expect any substantial developmental changes. In this time, no major shifts in the structural organization of intelligence or transitions between developmental cycles would be expected (Makris et al., 2017). These results strengthen the conclusions based on the stability analyses, as they show that no major developmental changes occurred between the measurements that would challenge the assumption of temporal stability of ability profiles.

\section{Strengths and Limitations}

The present study makes important contributions to research on the stability of individual strengths and weaknesses in intelligence testing. First, whereas most previous studies investigated samples of below average ability individuals, we examined the results from a high

ability sample. Second, our study included analyses of mean-level change, individual-level change, differential continuity, and ipsative continuity to provide a more complete picture of temporal stability. Third, in our analyses of the differential continuity we investigated the autocorrelations of the specific abilities as well as the partial autocorrelations controlling for general intelligence. Fourth, in our analyses of ipsative continuity we used two different measures to ensure comparability with previous research, but also to address potential distortions of the kappa statistic.

There are also some limitations to the present study. First, we investigated only a moderately sized sample from a single German school. Further research is needed to test the generalizability of our findings to other high ability samples. Nonetheless, our study shows that for some populations the reliability of intelligence test specific ability scores is higher than 
previously reported for low-ability and average ability populations. In addition, research on the temporal stability of intelligence profiles suffers from small sample sizes and the lack of control groups. We trust that our study encourages future research that investigates wider sections of the ability distribution with larger samples.

Second, the test-retest interval of six months only allowed us to investigate medium-term stability. To assess the long-term stability of specific ability scores, a test-retest interval of two years or longer is needed. However, our results show greater stability than other analyses of medium-term stability (e.g., Ryan et al, 2010; Watkins \& Canivez, 2004).

Third, the BIS-HB is a German test that might be unfamiliar to international researchers and practitioners. However, the BIS-HB is a test instrument that has the psychometric properties required for objective, reliable, and valid intelligence testing and is particularly appropriate for the testing of high ability individuals (Jäger et al., 2006). Moreover, the multidimensionality of the test and the calculation of the specific ability scores is similar to those of many more widely used intelligence tests such as the Wechsler tests of intelligence. Still, our analyses need to be replicated with different intelligence tests to examine the generalizability of our findings.

Fourth, due to the limited sample size we did not apply latent modeling techniques such as structural equation models to examine the variance proportions accounted for by the $g$-factor and the group factors, respectively. However, the present study aimed to examine the temporal stability of the manifest scores practitioners use in everyday diagnostic practice and previous research on the reliability of specific ability scores was based on manifest test scores, too (e.g., Ryan et al., 2010; Watkins \& Canivez, 2004; Watkins \& Smith, 2013).

Fifth, we could not determine the true size of practice effects, which complicates the interpretation of mean-level and individual-level change. By using a true score estimate for the 
second test score we to some extent accounted for effects of practice in the analyses of individual-level change.

Sixth, our differentiation analyses were limited by the time interval and the test battery. Developmental changes in the structure of cognitive abilities may occur in specific developmental cycles and involve specific abilities (Makris et al., 2017). The BIS-HB is not specifically designed to detect these changes. Furthermore, the short time interval between measurements and the narrow age range of the participants make it likely that the data was largely collected within one developmental cycle, in which little change occurs.

\section{Theoretical Implications}

The results of the present study complement the results of other studies examining individual differences in the intelligence structure in other areas of intelligence research. The findings on SLODR have informed different kinds of analyses of ability-dependent differences in intelligence structure and ability profiles. While there is initial evidence supporting the increased incremental validity of specific ability scores (Breit \& Preckel, 2020; McGill, 2015) and compelling evidence for an increased prevalence of highly diversified intelligence profiles (Lohman et al., 2008) with increased cognitive ability, the present study marks the first indication of greater profile stability in high ability individuals. The current investigation focused on adolescents. Further research is needed to test the generalizability of the results to other age groups. Especially for children, the findings on SLODR are somewhat inconsistent (Breit, Preckel, \& Brunner, 2021). It is therefore unclear whether increased specific ability score stability with increasing ability will be observed in elementary school children. Of note, our analyses of differentiation effects showed an absence of SLODR in the data of the present study. 
This may be due to the highly selective sample that does not represent the full ability continuum. A study investigating SLODR in adolescents using the BIS-HB reported consistent albeit statistically nonsignificant findings indicating that the effect emerged during adolescence (Breit et al., 2020).

\section{Developmental Implications}

There are some tentative developmental implications of our study. First, the mean-level change results show that even though intelligence is generally assumed to be a stable trait, substantial gains, even in general intelligence, may be achievable. The size of true gains compared to practice effects cannot be determined. However, based on meta-analytic evidence (Scharfen et al., 2018), it is unlikely that the observed gains are completely based on practice effects. Second, specific ability scores and ability profiles were relatively stable over time. We did not find large shifts in the configuration of abilities in individuals, even when overall test performance increased. Importantly, the developmental implications of the present studies are limited by the short time interval between the two measurement points and the small sample size. Further research is needed to corroborate the findings.

\section{Practical Implications}

Based on the research on SLODR, Reynolds (2013) tentatively recommended interpreting intelligence profiles in high ability individuals. However, evidence regarding the validity and reliability of these profiles was necessary to support this recommendation. The present study indicates that the stability of high ability individuals' intelligence profiles is sufficient for individual diagnostic decisions. This finding implies that at least for the top $15 \%$ of the intelligence distribution, the interpretation of intelligence profiles may not be hindered by insufficient temporal stability of the scores. Evidence for the validity of intelligence profiles for 
individuals in this section of the ability distribution was provided by analyses of the incremental validity of specific ability scores (Breit \& Preckel, 2020; McGill, 2015). Interpreting the ability profiles goes along with a modified use of the general intelligence score, as this score is no longer the only criteria for diagnostic decisions. Our results tentatively support that both the level of general intelligence and ability profiles add valuable diagnostic information when testing high ability individuals.

\section{Conclusion}

Previous research has shown little temporal stability of intelligence specific ability scores. Based on findings that show ability-dependent individual differences in the intelligence structure, we investigated the temporal stability of specific ability scores in a high ability sample. Our results indicate sufficient stability for individual diagnostic decisions in high ability individuals. Since our results contradict the findings of previous studies with low ability samples, we see a need for further research examining large samples with heterogeneous ability levels. 


\section{References}

Algozzine, B., Eaves, R. C., Mann, L., \& Vance, H. R. (1993). Slosson Full-Range Intelligence Test (S-FRIT). New York, NY: Slosson Educational Publications.

Beauducel, A., \& Kersting, M. (2002). Fluid and crystallized intelligence and the Berlin Model of Intelligence Structure (BIS). European Journal of Psychological Assessment, 18(2), 97-112. https://doi.org/10.1027//1015-5759.18.2.97

Blum, D., \& Holling, H. (2017). Spearman's law of diminishing returns. A meta-analysis. Intelligence, 65, 60-66. http://dx.doi.org/0.1016/j.intell.2017.07.004

Breit, M., Brunner, M., \& Preckel, F. (2020). General intelligence and specific cognitive abilities in adolescence: Tests of developmental differentiation, ability differentiation, and their interaction in two large samples. Developmental Psychology, 56(2), 364-384. http://dx.doi.org/10.1037/dev0000876

Breit, M., Scherrer, V., \& Preckel, F. (2021). Temporal Stability of Specific Ability Scores and Intelligence Profiles. Manuscript submitted for publication.

Breit, M., Brunner, M., \& Preckel, F. (2021). Age and ability differentiation in children: A review and empirical investigation. Developmental Psychology. https://doi.org/10.1037/dev0001147

Breit, M., \& Preckel, F. (2020). Incremental validity of specific cognitive abilities beyond general intelligence for the explanation of students' school achievement. Gifted and Talented International. https://doi.org/10.1080/15332276.2020.1799454

Byrt, T., Bishop, J., \& Carlin, J. B. (1993). Bias, prevalence and kappa. Journal of Clinical Epidemiology, 46(5), 423-429. http://dx.doi.org/10.1016/0895-4356(93)90018-v 
Cohen, J. (1960). A coefficient of agreement for nominal scales. Educational and Psychological Measurement, 20, 37-46. http://dx.doi.org/10.1177/001316446002000104

Canivez, G. L., \& Youngstrom, E. A. (2019) Challenges to the Cattell-Horn-Carroll Theory: Empirical, Clinical, and Policy Implications, Applied Measurement in Education, 2:3, 232-248, http://dx.doi.org/10.1080/08957347.2019.1619562

Cronbach, L. J., \& Snow, R. E. (1977). Aptitudes and instructional methods: A handbook for research on interactions. New York, NY: Irvington.

Estevis, E., Basso, M. R., \& Combs, D. (2012). Effects of practice on the Wechsler Adult Intelligence Scale-IV across 3- and 6-month intervals. The Clinical Neuropsychologist, 26(2), 239-254. http://dx.doi.org/10.1080/13854046.2012.659219

Freund, P. A. \& Holling, H. (2007). Creativity in the classroom: A multilevel analysis investigating the impact of creativity and reasoning ability on scholastic achievement. Creativity Research Journal, 20(3), 309-318. http://dx.doi.org/10.1080/10400410802278776

Freund, P. A., Holling, H., \& Preckel, F. (2007). A multivariate, multilevel analysis of the relationship between cognitive abilities and scholastic achievement. Journal of Individual Differences, 28, 188-197. http://dx.doi.org/10.1027/1614-0001.28.4.188

Fryer, J. W., \& Elliot, A. J. (2007). Stability and change in achievement goals. Journal of Educational Psychology, 99(4), 700-714. http://dx.doi.org/10.1037/e633962013-763

Garrett, H. E. (1946). A developmental theory of intelligence. American Psychologist, 1(9), 372378. https://doi.org/10.1037/h0056380 
Hartmann, P. \& Nyborg, H. (2004). Spearman's "Law of Diminishing Returns ": A critical eye on a century of methods, results, and current standing of the theory. Unpublished manuscript, University of Aarhus, Aarhus.

Hunt, E. (2010). Human intelligence. New York, NY: Cambridge University Press.

Iverson, G. L. (2018, November 28). Reliable Change Index. Encyclopedia of Clinical Neuropsychology. Retrived February 4 from https://link.springer.com/referenceworkentry/10.1007\%2F978-3-319-56782-2_1242-3

Jacobson, N. S., \& Truax, P. (1991). Clinical significance: A statistical approach to defining meaningful change in psychotherapy research. Journal of Consulting and Clinical Psychology, 59(1), 12-19. http://dx.doi.org/10.1037/0022-006x.59.1.12

Jäger, A. O. (1984). Intelligenzstrukturforschung: Konkurrierende Modelle, neue Entwicklungen, Perspektiven [Intelligence structure research: competing models, new developments, perspectives]. Psychologische Rundschau.

Jäger, A. O., Holling, H., Preckel, F., Schulze, R., Vock, M., Süß, H.-M. \& Beauducel, A. (2006). Berliner Intelligenzstruktur-Test für Jugendliche: Begabungs- und Hochbegabungsdiagnostik (BIS-HB) [Berlin structure of intelligence test for youth: Assessment of talent and giftedness]. Göttingen: Hogrefe. http://dx.doi.org/10.1026/00121924.54.4.221

Kaufman, A. S. (2004). Kaufman Assessment Battery for Children, (KABCTM-II).

Lander, J. (2010). Long-term stability of scores on the Wechsler Intelligence Scale for Children-Fourth Edition in children with learning disabilities. Dissertation Abstracts International: Section A. Humanities and Social Sciences. 
Landis, J. R., \& Koch, G. G. (1977). An application of hierarchical kappa-type statistics in the assessment of majority agreement among multiple observers. Biometrics, 363-374. http://dx.doi.org/10.2307/2529786

Lienert, G. A. (1989). Testaufbau und Testanalyse (4. Aufl.) [Test construction and test analysis]. Psychologie-Verlags-Union (PVU).

Lienert, G. A. \& Raatz, U. (1998). Testaufbau und Testanalyse [Test construction and test analysis]. Weinheim: Psychologie-Verlags-Union (PVU).

Lohman, D. F., Gambrell, J., \& Lakin, J. (2008). The commonality of extreme discrepancies in the ability profiles of academically gifted students. Psychology Science, 50(2), 269-282.

Lubinski, D. (2010). Spatial ability and STEM: A sleeping giant for talent identification and development. Personality and Individual Differences, 49(4), 344-351. http://dx.doi.org/10.1016/j.paid.2010.03.022

Lubinski, D. (2016). From Terman to Today. Review of Educational Research, 86(4), 900-944. http://dx.doi.org/10.3102/0034654316675476

Lubinski, D., \& Benbow, C. P. (2006). Study of mathematically precocious youth after 35 years: Uncovering antecedents for the development of math-science expertise. Perspectives on Psychological Science, 1, 316-345. http://dx.doi.org/10.1111/j.1745-6916.2006.00019.x

Lubinski, D., Webb, R. M., Morelock, M. J., \& Benbow, C. P. (2001). Top 1 in 10,000: A 10-year follow-up of the profoundly gifted. Journal of Applied Psychology, 86(4), 718-729. http://dx.doi.org/10.1037/0021-9010.86.4.718

Mackintosh, N. J. (1998). IQ and human intelligence. New York, NY: Oxford University Press. McCrae, R. R. (2008). A note on some measures of profile agreement. Journal of Personality Assessment, 90(2), 105-109. https://doi.org/10.1080/00223890701845104 
McDermott, P. A., Fantuzzo, J. W., Glutting, J. J., Watkins, M. W., \& Baggaley, A. R. (1992). Illusions of meaning in the ipsative assessment of children's ability. The Journal of Special Education, 25(4), 504-526. http://dx.doi.org/10.1177/002246699202500407

McGill, R. J. (2015). Spearman's Law of Diminishing Returns (SLODR): Examining effects at the level of prediction. Journal of Psychology and Behavioral Science, 3(1), 24-36. http://dx.doi.org/10.15640/jpbs.v3n1a3

Makel, M. C., Kell, H. J., Lubinski, D., Putallaz, M., \& Benbow, C. P. (2016). When lightning strikes twice. Psychological Science, 27(7), 1004-1018. http://dx.doi.org/10.1177/0956797616644735

Molenaar, D., Dolan, C. V., Wicherts, J. M., \& van der Maas, H. L. J. (2010). Modeling differentiation of cognitive abilities within the higher-order factor model using moderated factor analysis. Intelligence, 38(6), 611-624. http://dx.doi.org/10.1016/j.intell.2010.09.002

Molenaar, D. (2020). A flexible moderated factor analysis approach to test for measurement invariance across a continuous variable. Psychological Methods. http://dx.doi.org/10.1037/met0000360

Nisbett, R. E., Aronson, J., Blair, C., Dickens, W., Flynn, J., Halpern, D. F., \& Turkheimer, E. (2012). Intelligence: New findings and theoretical developments. American Psychologist, 67(2), 130-159. http://dx.doi.org/10.1037/a0026699

Preckel, F., Holling, H., \& Wiese, M. (2006). Intelligence and creativity in gifted and non-gifted students: An investigation of threshold theory. Personality and Individual Differences, 40(1), 159-170. http://dx.doi.org/10.1016/j.paid.2005.06.022 
Reynolds, M. R. (2013). Interpreting the g loadings of intelligence test composite scores in light of Spearman's law of diminishing returns. School Psychology Quarterly, 28(1), 63-76. http://dx.doi.org/10.1037/spq0000013

Roberts, B. W., Walton, K. E., \& Viechtbauer, W. (2006). Patterns of mean-level change in personality traits across the life course: A meta-analysis of longitudinal studies. Psychological Bulletin, 132(1), 1-25. http://dx.doi.org/10.1037/0033-2909.132.1.1

Preckel, F., Wermer, C., \& Spinath, F. M. (2011). The interrelationship between speeded and unspeeded divergent thinking and reasoning, and the role of mental speed. Intelligence, 39, 378-388. http://dx.doi.org/10.1016/j.intell.2011.06.007

Robertson, K. F., Smeets, S., Lubinski, D., \& Benbow, C. P. (2010). Beyond the Threshold Hypothesis. Current Directions in Psychological Science, 19(6), 346-351. http://dx.doi.org/10.1177/0963721410391442

Ryan, J. J., Glass, L. A., \& Bartels, J. M. (2010). Stability of the WISC-IV in a sample of elementary and middle school children. Applied Neuropsychology, 17, 68-72. http://dx.doi.org/10.1080/09084280903297933

Scharfen, J., Peters, J. M., \& Holling, H. (2018). Retest effects in cognitive ability tests: A metaanalysis. Intelligence, 67, 44-66. http://dx.doi.org/10.1016/j.intell.2018.01.003

Schneider, W. J. \& McGrew, K. S. (2018). The Cattell-Horn-Carroll theory of cognitive abilities. In D. P. Flanagan \& E. M. McDonough (Hrsg.), Contemporary intellectual assessment: Theories, tests, and issues (S. 73-163). New York, NY: The Guilford Press.

Schroeders, U., Schipolowski, S., \& Wilhelm, O. (2015). Age-related changes in the mean and covariance structure of fluid and crystallized intelligence in childhood and adolescence. Intelligence, 48, 15-29. https://doi.org/10.1016/j.intell.2014.10.006 
Süß, H. -M., \& Beauducel, A. (2005). Faceted models of intelligence. In O. Wilhelm \& R. W. Engle (Eds.), Handbook of understanding and measuring intelligence (pp. 313-332). Thousand Oaks: Sage. http://dx.doi.org/10.4135/9781452233529.n18

Terracciano, A., \& McCrae, R. R. (2006). How to measures national stereotypes? Response. Science, 311, 777-779.

Tucker-Drob, E. M. (2009). Differentiation of cognitive abilities across the life span. Developmental Psychology, 45(4), 1097-1118. httpss://doi.org/10.1037/a0015864

Vock, M., Preckel, F., \& Holling, H. (2011). Mental abilities and school achievement: A test of a mediation hypothesis. Intelligence, 39(5), 357-369. http://dx.doi.org/10.1016/j.intel1.2011.06.006

Watkins, M. W., \& Canivez, G. L. (2004). Temporal stability of WISC-III subtest composite strengths and weaknesses. Psychological Assessment, 16(2), 133-138. http://dx.doi.org/10.1037/1040-3590.16.2.133

Watkins, M. W., \& Smith, L. (2013). Long-term stability of the Wechsler Intelligence Scale for Children - Fourth Edition. Psychological Assessment, 25(2), 477-483. http://dx.doi.org/10.1037/a0031653

Wechsler, D. (2014). Wechsler intelligence scale for children - Fifth edition technical and interpretive manual. San Antonio, TX: NCS Pearson.

Williams Jr, T. O., Eaves, R. C., Woods-Groves, S., \& Mariano, G. (2007). Stability of scores for the Slosson full-range intelligence test. Psychological Reports, 101(1), 135-140. https://doi.org/10.2466/pr0.101.1.135-140

Wirtz, M., \& Caspar, F. (2002). Beurteilerübereinstimmung und Beurteilerreliabilität.[Inter-rater agreement and inter-rater reliability]. Göttingen: Hogrefe. 
Tables

Table 1. Methodological Overview of Different Types of Temporal Stability

\begin{tabular}{|c|c|c|}
\hline $\begin{array}{l}\text { Type of } \\
\text { Stability }\end{array}$ & Description & Applied methods in the present article \\
\hline $\begin{array}{l}\text { Mean-level } \\
\text { change }\end{array}$ & $\begin{array}{l}\text { The average } \\
\text { change in one } \\
\text { variable across } \\
\text { time within a } \\
\text { sample. }\end{array}$ & $\begin{array}{l}\text { Paired-samples } t \text {-test: Tests whether the observed difference } \\
\text { between two points of measurement significantly differs from } \\
\text { zero. } \\
\text { Cohen's } d \text { : Standardizes the difference in the average score of a } \\
\text { group across time based on the standard deviation of the score at } \\
\text { the first measurement point }\left(S D_{\mathrm{t} 1}\right) \text {. }\end{array}$ \\
\hline $\begin{array}{l}\text { Individual- } \\
\text { level change }\end{array}$ & $\begin{array}{l}\text { Assesses the } \\
\text { reliability of } \\
\text { change in } \\
\text { individuals. }\end{array}$ & $\begin{array}{l}\text { - Individual-level change based on the standard error of the } \\
\text { prediction }\left(S E_{\text {pred }}\right) \text { : Estimates the significance of the individual } \\
\text { change. The formula is based on the assumption that T1 and T2 } \\
\text { values correlate with each other and that practice effects are } \\
\text { evident. } \\
\text { Individual-level change based on the standard error of the } \\
\text { difference }\left(S E_{\text {diff }}\right) \text { surrounding the T1-T2 difference scores: } S E_{\text {diff }} \\
\text { is used to create a confidence interval and to test whether } \\
\text { individual difference scores exceed this confidence interval. As } \\
\text { practice effects were assumed to be irrelevant in the initial } \\
\text { formula (which was developed to test the individual benefits in } \\
\text { psychotherapy), we used a true score estimator that takes into } \\
\text { account possible practice effects. }\end{array}$ \\
\hline $\begin{array}{l}\text { Differential } \\
\text { continuity }\end{array}$ & $\begin{array}{l}\text { Degree to which } \\
\text { the relative } \\
\text { order of } \\
\text { individuals on a } \\
\text { given trait is } \\
\text { maintained } \\
\text { across time } \\
\text { (rank-order } \\
\text { consistency). }\end{array}$ & $\begin{array}{l}\text { - Auto-correlation (T1-T2 correlations of the same trait) of a } \\
\text { specific ability or general intelligence: } r=1 \text { means that all } \\
\text { individuals kept their rank relative to other persons; } r=0 \text { means } \\
\text { that the rank order in } \mathrm{T} 1 \text { is not systematically related to the rank } \\
\text { order in T2. } \\
\text { Auto-correlation of a specific ability controlled for general } \\
\text { intelligence: In this approach, the observed partial auto- } \\
\text { correlation is independent of general intelligence (i.e., it cannot } \\
\text { be explained by the stability of general intelligence). } \\
\text { Auto-correlation of a specific ability or general intelligence } \\
\text { corrected for range restriction. This approach takes into account } \\
\text { the restriction of variance in selective samples. }\end{array}$ \\
\hline $\begin{array}{l}\text { Ipsative } \\
\text { continuity }\end{array}$ & $\begin{array}{l}\text { Continuity in } \\
\text { the } \\
\text { configuration of } \\
\text { different } \\
\text { variables within } \\
\text { one individual } \\
\text { across time. }\end{array}$ & $\begin{array}{l}\text { - Cohen's kappa: Estimates whether individual strengths or } \\
\text { weaknesses regarding one specific ability (relative to the general } \\
\text { intelligence score) were classified as the same across both times } \\
\text { of measurement. Possible values range from }-1 \text { to }+1 \text {. The value } \\
\text { of } 1 \text { means that the observed strengths and weaknesses of all } \\
\text { persons were the same at } \mathrm{T} 1 \text { and T2. The value of } 0 \text { means that } \\
\text { there is no observed agreement between strengths and } \\
\text { weaknesses across time. } \\
\text { Cramér's V: Estimates whether intrapersonal strengths or } \\
\text { weaknesses regarding one specific ability were stable over time. } \\
\text { In contrast to Kappa, Cramér's V is not affected by an uneven } \\
\text { distribution of the classification categories. It can be interpreted } \\
\text { similar to a correlation coefficient. }\end{array}$ \\
\hline
\end{tabular}


Table 2. Correlations Between all BIS-HB Ability Scores at Test and Retest

\begin{tabular}{|c|c|c|c|c|c|c|c|c|}
\hline & $\bar{S}$ & $\bar{M}$ & $\bar{C}$ & $\mathrm{R}$ & $\bar{F}$ & $\bar{N}$ & $\bar{V}$ & IQ \\
\hline \multirow[t]{8}{*}{ Test } & $S$ & .44 & .50 & .41 & .65 & .71 & .59 & .76 \\
\hline & $\mathrm{M}$ & & .35 & .40 & .55 & .66 & .59 & .70 \\
\hline & $\mathrm{C}$ & & & .29 & .63 & .55 & .65 & .71 \\
\hline & $\mathrm{R}$ & & & & .63 & .67 & .65 & .76 \\
\hline & $\mathrm{F}$ & & & & & .61 & .56 & .83 \\
\hline & $\mathrm{N}$ & & & & & & .63 & .88 \\
\hline & $\mathrm{V}$ & & & & & & & .84 \\
\hline & IQ & & & & & & & \\
\hline \multirow[t]{8}{*}{ Retest } & $S$ & .46 & .54 & .35 & .57 & .62 & .76 & .76 \\
\hline & M & & .26 & .44 & .60 & .58 & .63 & .70 \\
\hline & $\mathrm{C}$ & & & .24 & .67 & .58 & .52 & .69 \\
\hline & $\mathrm{R}$ & & & & .59 & .70 & .61 & .74 \\
\hline & $\mathrm{F}$ & & & & & .59 & .56 & .84 \\
\hline & $\mathrm{N}$ & & & & & & .61 & .85 \\
\hline & $\mathrm{V}$ & & & & & & & .85 \\
\hline & IQ & & & & & & & \\
\hline
\end{tabular}

Note. All correlations $p<.01 . \mathrm{S}=$ Processing Speed, $\mathrm{M}=$ Memory, $\mathrm{C}=$ Creativity, $\mathrm{R}=$

Reasoning, $\mathrm{F}=$ Figural Ability, $\mathrm{N}=$ Numerical Ability, $\mathrm{V}=$ Verbal Ability, $\mathrm{IQ}=$ General Intelligence 
Table 3. Means and Standard Deviations of BIS-HB Specific Ability Scores Across a TestRetest Interval of Six Months

\begin{tabular}{|c|c|c|c|c|c|c|}
\hline \multirow[b]{2}{*}{ Ability Score } & \multicolumn{2}{|c|}{ Test } & \multicolumn{2}{|c|}{ Retest } & \multirow[b]{2}{*}{ Difference } & \multirow[b]{2}{*}{$d$} \\
\hline & $M$ & $S D$ & $M$ & $S D$ & & \\
\hline Processing Speed & 112.15 & 11.00 & 122.42 & 12.27 & 10.27 & 0.93 \\
\hline Memory & 113.57 & 12.80 & 121.75 & 12.09 & 8.18 & 0.64 \\
\hline Creativity & 109.15 & 12.66 & 116.34 & 13.04 & 7.19 & 0.57 \\
\hline Reasoning & 118.04 & 9.96 & 123.63 & 9.64 & 5.60 & 0.56 \\
\hline Figural Ability & 112.59 & 11.88 & 122.88 & 11.28 & 10.29 & 0.87 \\
\hline Numeric Ability & 116.71 & 10.33 & 123.70 & 9.65 & 6.88 & 0.67 \\
\hline Verbal Ability & 115.56 & 9.66 & 122.56 & 10.18 & 7.01 & 0.73 \\
\hline General Intelligence & 116.72 & 9.97 & 125.48 & 9.61 & 8.78 & 0.88 \\
\hline
\end{tabular}

Note. All differences $p<.001$ 
Table 4. Skewness and Kurtosis of BIS-HB Specific Ability Scores

\begin{tabular}{lccccc}
\hline \multirow{2}{*}{ Ability Score } & \multicolumn{2}{c}{ Test } & & \multicolumn{2}{c}{ Retest } \\
\cline { 2 - 3 } \cline { 5 - 6 } Processing Speed & -.12 & .52 & & -.18 & -.42 \\
Memory & -.52 & .29 & & -.42 & -.20 \\
Creativity & .12 & -.21 & & -.13 & -.37 \\
Reasoning & .11 & .11 & & -.27 & -.61 \\
Figural & -.18 & .35 & & -.02 & -.31 \\
Numerical & -.25 & 1.03 & & -.32 & -.11 \\
Verbal & .14 & -.12 & & -.24 & -.32 \\
General Intelligence & .21 & .42 & & .00 & -.67 \\
Standard Error & .23 & .45 & & .23 & .45 \\
\hline
\end{tabular}


Table 5. Reliable Change of the BIS-HB Specific Ability Scores

\begin{tabular}{|c|c|c|c|c|}
\hline & Ability Score & $\%$ decrease & $\%$ same & $\%$ increase \\
\hline \multirow[t]{8}{*}{$\mathrm{SE}_{\text {pred }}$} & Processing Speed & 0 & 76.3 & 23.7 \\
\hline & Memory & 0 & 88.6 & 11.4 \\
\hline & Creativity & 1.8 & 93.0 & 5.3 \\
\hline & Reasoning & 0.9 & 83.3 & 15.8 \\
\hline & Figural Ability & 0 & 78.9 & 21.1 \\
\hline & Numeric Ability & 0.9 & 80.7 & 19.3 \\
\hline & Verbal Ability & 0 & 88.6 & 11.4 \\
\hline & General Intelligence & 0.9 & 68.4 & 30.7 \\
\hline \multirow[t]{8}{*}{$S E_{\text {diff }}$} & Processing Speed & 0 & 76.3 & 23.7 \\
\hline & Memory & 0 & 88.6 & 11.4 \\
\hline & Creativity & 0.9 & 94.7 & 4.4 \\
\hline & Reasoning & 0 & 88.6 & 11.4 \\
\hline & Figural Ability & 0 & 80.7 & 19.3 \\
\hline & Numeric Ability & 0.9 & 86.0 & 13.2 \\
\hline & Verbal Ability & 0 & 88.6 & 11.4 \\
\hline & General Intelligence & 0 & 70.2 & 29.8 \\
\hline
\end{tabular}


Table 6. Differential Continuity Coefficients and Differential Continuity Coefficients controlling for General Intelligence of the BIS-HB Specific Ability Scores

\begin{tabular}{lccc}
\hline Ability Score & $r_{12}$ & $r_{12 . g}$ & $r_{12 c}$ \\
\hline Processing Speed & .84 & .66 & .91 \\
Memory & .74 & .59 & .80 \\
Creativity & .72 & .55 & .78 \\
Reasoning & .84 & .69 & .93 \\
Figural Ability & .77 & .51 & .85 \\
Numeric Ability & .82 & .53 & .91 \\
Verbal Ability & .81 & .49 & .91 \\
Average $r$ & .79 & .57 & .87 \\
General Intelligence & .85 & - & .93 \\
\hline
\end{tabular}

$\overline{\text { Note. All coefficients } p<.01 \text {. Correction for range restriction }}$ was based on the variability in the normative sample.

$r_{12}=$ uncorrected autocorrelation, $r_{12 . g}=$ partial autocorrelation controlled for the general intelligence, $r_{12 c}=$ autocorrelation corrected for range restriction 
Table 7. Agreement on BIS-HB Ability Score-Based Strengths and Weaknesses Across a Test-Retest Interval of 6 Months

\begin{tabular}{llc}
\hline Ability Score & $K$ & $\mathrm{~V}$ \\
\hline Processing Speed & $.25^{* *}$ & $.22^{*}$ \\
Memory & $.29^{* *}$ & $.33^{* *}$ \\
Creativity & $.58^{* * *}$ & $.65^{* * *}$ \\
Reasoning & $.34^{* * *}$ & $.43^{* * *}$ \\
Figural Ability & $.34^{* * *}$ & $.45^{* * *}$ \\
Numeric Ability & N.A. & N.A. \\
Verbal Ability & $.23^{* *}$ & $.30^{* *}$ \\
Mdn $\kappa$ & .32 & \\
\hline Note. $* p<.05, * * p<.01, * * * p<.001 . \kappa=$ Cohen's kappa, \\
V $=$ Cramér's V. N.A. $=$ not available because of 0 identified \\
strengths and weaknesses at T1
\end{tabular}


Table 8. Model Comparison: Tested Parameters and Fit Statistics

\begin{tabular}{llllll}
\hline & Model 1 & Model 2a & Model 2b & Model 3 & Model 4 \\
\cline { 2 - 6 } $\begin{array}{l}\text { Tested } \\
\text { Parameters }\end{array}$ & $\begin{array}{l}\text { Linear } \\
\text { Model }\end{array}$ & Ability Diff & No Age Diff & $\begin{array}{l}\text { Ability Diff \& } \\
\text { No Age Diff }\end{array}$ & $\begin{array}{l}\text { Ability Diff } \\
\text { \& No Age } \\
\text { Diff \& No } \\
\text { Interaction }\end{array}$ \\
\hline Log likelihood & -1007.714 & -1003.954 & -1008.873 & -1005.372 & -1005.708 \\
Free parameters & 29 & 37 & & & 29 \\
$\chi^{2}$ of difference & & -3.760 & 4.919 & 33 & 0.336 \\
$d f$ of difference & & 12 & -4 & -4 & -4 \\
AIC & 2073.429 & 2081.908 & $\mathbf{2 0 6 7 . 7 4 6}$ & $\mathbf{2 0 7 6 . 7 4 4}$ & $\mathbf{2 0 6 9 . 4 1 7}$ \\
BIC & 2152.779 & 2183.148 & $\mathbf{2 1 3 6 . 1 5 1}$ & $\mathbf{2 1 6 7 . 0 3 8}$ & $\mathbf{2 1 4 8 . 7 6 6}$ \\
SABIC & 2061.120 & 2066.203 & $\mathbf{2 0 5 7 . 1 3 5}$ & $\mathbf{2 0 6 2 . 7 3 6}$ & $\mathbf{2 0 5 7 . 1 0 7}$ \\
Comparison & - & Model 1 & Model 1 & Model 2a & Model 3 \\
model & & & & & \\
\hline
\end{tabular}

Notes. $* p<.01$. A value of a certain information criterion is highlighted in bold face to indicate if the target model is supported by AIC (Akaike information criterion), BIC (Bayesian information criterion), or SABIC (sample-sizeadjusted BIC) relative to the comparison model. Ability Diff $=$ The model depicted the main effect of ability differentiation. No Age Diff $=$ The model and prohibited variations in $g$-factor loadings between the different times of measurement (prohibiting developmental differentiation). Ability Diff \& No Age Diff $=$ The model depicted the main effects of ability differentiation and prohibited variations in $g$-factor loadings between the different times of measurement (prohibiting developmental differentiation). Ability Diff \& Age Diff \& Interaction $=$ The model depicted the main effects of ability differentiation, prohibited variations in $g$-factor loadings between the different times of measurement (prohibiting developmental differentiation) and prohibited variations in $g^{2}$-factor loadings between the different times of measurement (prohibiting the interaction effect). 
Table 9. Standardized Parameter Estimates (and 99\% Confidence Intervals) From Models 1-4

\begin{tabular}{|c|c|c|c|c|c|c|c|c|}
\hline \multirow[b]{2}{*}{$\bar{G}[\mathrm{x}]$} & \multirow{2}{*}{$\begin{array}{c}\text { Model } 1 \\
\lambda_{1}\end{array}$} & \multicolumn{2}{|c|}{ Model 2a } & \multirow{2}{*}{$\begin{array}{c}\text { Model 2b } \\
\lambda_{1}\end{array}$} & \multicolumn{2}{|c|}{ Model 3} & \multicolumn{2}{|c|}{ Model 4} \\
\hline & & $\lambda_{1}$ & $\lambda_{2}$ & & $\lambda_{1}$ & $\lambda_{2}$ & $\lambda_{1}$ & $\lambda_{2}$ \\
\hline \multirow[t]{2}{*}{ Speed 1} & 0.798 & 0.786 & -0.013 & $0.803^{\mathrm{a}}$ & $0.805^{\mathrm{a}}$ & -0.014 & $0.806^{\mathrm{a}}$ & $-0.022^{\mathrm{e}}$ \\
\hline & $(0.594,1.003)$ & $(0.583,0.990)$ & $(-0.140,0.114)$ & $(0.627,0.978)$ & $(0.637,0.973)$ & $(-0.133,0.105)$ & $(0.640,0.973)$ & $(-0.120,0.077)$ \\
\hline \multirow[t]{2}{*}{ Memory 1} & 0.586 & 0.615 & -0.049 & $0.574^{b}$ & $0.597^{b}$ & -0.042 & $0.593^{b}$ & $-0.023^{\mathrm{f}}$ \\
\hline & $(0.374,0.797)$ & $(0.374,0.857)$ & $(-0.263,0.165)$ & $(0.374,0.774)$ & $(0.371,0.824)$ & $(-0.264,0.180)$ & $(0.389,0.797)$ & $(-0.204,0.159)$ \\
\hline \multirow[t]{2}{*}{ Creativity 1} & 0.611 & 0.603 & 0.030 & $0.619^{c}$ & $0.610^{c}$ & 0.035 & $0.611^{\mathrm{c}}$ & $0.026^{\mathrm{g}}$ \\
\hline & $(0.412,0.811)$ & $(0.399,0.806)$ & $(-0.154,0.213)$ & $(0.460,0.778)$ & $(0.449,0.772)$ & $(-0.145,0.215)$ & $(0.453,0.768)$ & $(-0.106,0.159)$ \\
\hline \multirow[t]{2}{*}{ Reasoning 1} & 0.506 & 0.523 & 0.150 & $0.495^{d}$ & $0.512^{\mathrm{d}}$ & 0.145 & $0.512^{\mathrm{d}}$ & $0.144^{\mathrm{h}}$ \\
\hline & $(0.268,0.743)$ & $(0.303,0.743)$ & $(-0.022,0.323)$ & $(0.267,0.723)$ & $(0.303,0.720)$ & $(-0.020,0.311)$ & $(0.305,0.718)$ & $(-0.002,0.289)$ \\
\hline \multirow[t]{2}{*}{ Speed 2} & 0.852 & 0.853 & -0.022 & $0.814^{a}$ & $0.824^{\mathrm{a}}$ & -0.021 & $0.822^{\mathrm{a}}$ & $-0.022^{\mathrm{e}}$ \\
\hline & $(0.636,1.068)$ & $(0.656,1.050)$ & $(-0.176,0.132)$ & $(0.637,0.992)$ & $(0.651,0.997)$ & $(-0.170,0.128)$ & $(0.652,0.991)$ & $(,-0.1230 .078)$ \\
\hline \multirow[t]{2}{*}{ Memory 2} & 0.531 & 0.547 & 0.004 & $0.568^{b}$ & $0.584^{b}$ & 0.010 & $\mathbf{0 . 5 8 3}^{\mathrm{b}}$ & $-0.022^{f}$ \\
\hline & $(0.287,0.774)$ & $(0.309,0.786)$ & $(-0.181,0.189)$ & $(0.366,0.770)$ & $(0.361,0.808)$ & $(-0.172,0.193)$ & $(0.381,0.786)$ & $(-0.201,0.157)$ \\
\hline \multirow[t]{2}{*}{ Creativity 2} & 0.617 & 0.608 & -0.005 & $0.618^{c}$ & $0.610^{c}$ & 0.015 & $0.609^{c}$ & $0.026^{\mathrm{g}}$ \\
\hline & $(0.438,0.797)$ & $(0.421,0.794)$ & $(-0.255,0.246)$ & $(0.449,0.787)$ & $(0.439,0.781)$ & $(-0.218,0.249)$ & $(0.443,0.775)$ & $(-0.106,0.159)$ \\
\hline \multirow[t]{2}{*}{ Reasoning 2} & 0.438 & 0.608 & 0.133 & $0.484^{\mathrm{d}}$ & $0.494^{\mathrm{d}}$ & 0.146 & $0.494^{\mathrm{d}}$ & $0.139^{h}$ \\
\hline & $(0.162,0.715)$ & $(0.200,0.698)$ & $(-0.048,0.314)$ & $(0.253,0.716)$ & $(0.288,0.701)$ & $(-0.047,0.338)$ & $(0.291,0.698)$ & $(0.001,0.277)$ \\
\hline
\end{tabular}

Notes. Values in bold indicate $p<.01 . \lambda_{1}=$ factor loadings, $\lambda_{2}=$ ability differentiation parameters. Negative values of $\lambda_{2}$ indicate ability differentiation. Letters in superscript indicate unstandardized loadings that were restricted to be equal between T1 and T2. 
Figures

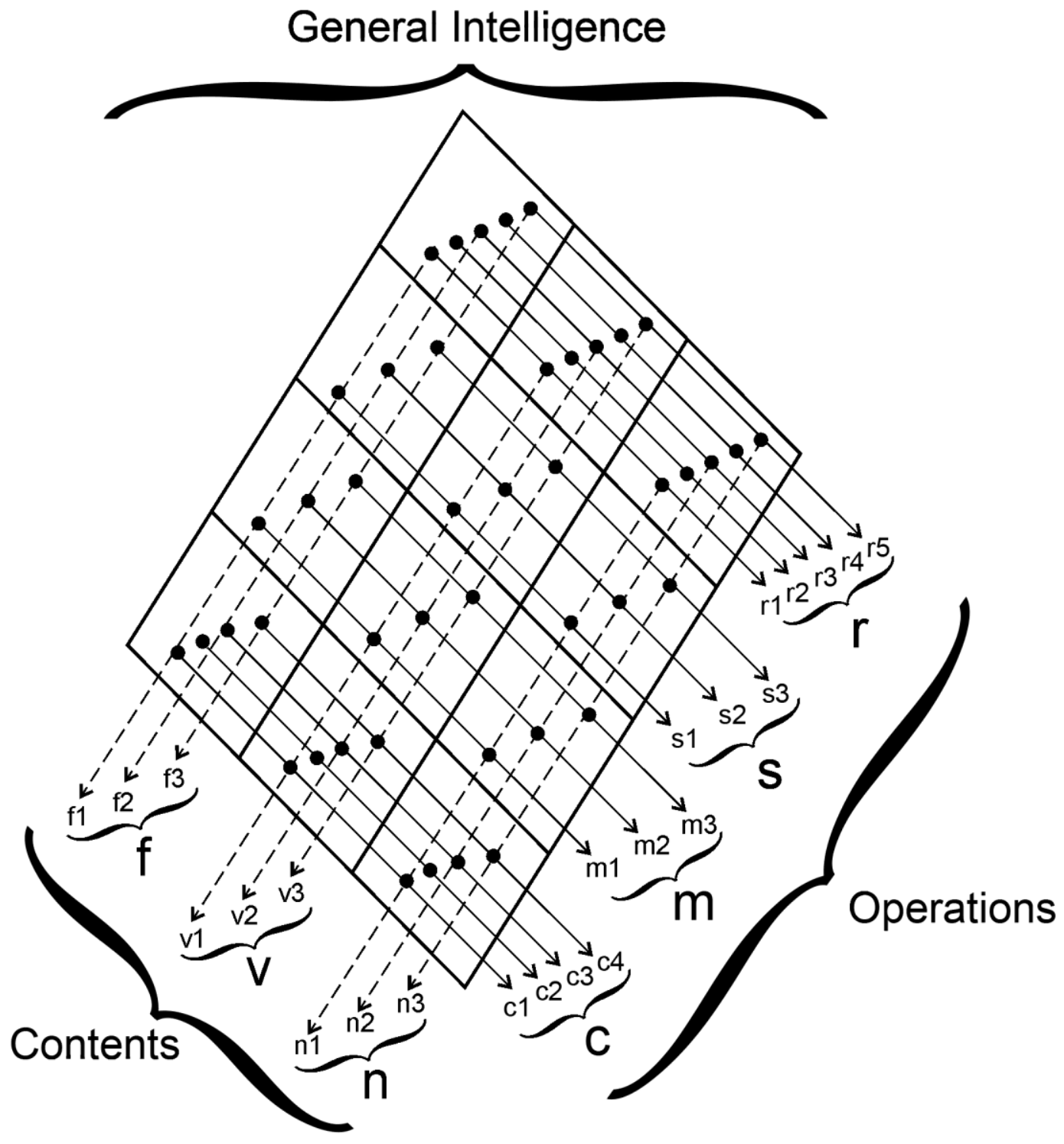

Figure 1. Structure of the Berlin model of Intelligence Structure (BIS). f= Figural Ability, v $=$ Verbal Ability, $\mathrm{n}=$ Numerical Ability, $\mathrm{r}=$ Reasoning, $\mathrm{s}=$ Processing Speed, $\mathrm{m}=$ Memory, $\mathrm{c}=$ Creativity. 